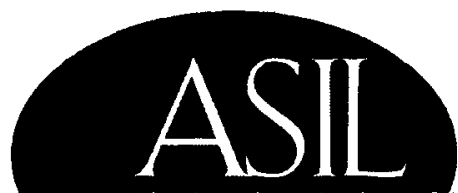

The American Society of International Law

VIOLENCE $93^{\text {rd }}$ Annual Meeting

March 24-27 1999 • ANA Hotel • Washington, DC

\title{
MONIY
}

Powor

CULTURE

\section{Reviewing the Internationalist Legacy}

Registration Fees

Non-member

-One-day

Member:

- Regular

- Special

- One-day

Student

Group Rate (8)

\section{Before Feb, 1, 1999}

$\$ 450$

$\$ 125$

$\$ 250$

$\$ 125$

$\$ 100$

$\$ 0$

$\$ 1,300$

After Feb. 1, 1999
$\$ 525$
$\$ 150$

$\$ 300$

$\$ 150$

$\$ 100$

$\$ 0$

$\$ 1,500$

\section{At Meeting \\ $\$ 550$ \\ $\$ 150$}

$\$ 325$

$\$ 175$

$\$ 125$

$\$ 0$

$\$ 1,800$

For more information about ASIL's Annual Meeting, the Society or membership information, please contact the Services Group at (202) 9396000 . Or, visit our Web site at www.asil.org. 